\title{
Leyes de medios de Chile y Argentina: tan cerca tan lejos
}

\author{
Pedro SANTANDER \\ Pontificia Universidad Católica de Valparaíso (Chile) \\ pedro.santander@ucv.cl
}

Recibido: $17 / 02 / 2013$

Aceptado: 09/09/2013

\begin{abstract}
Resumen
Esta investigación realiza un estudio comparativo entre las leyes de medios de Chile y la nueva Ley de Medios de Argentina. El objetivo es analizar cómo estos cuerpos legales consideran los principios de pluralismo y diversidad, cómo entienden la relación entre ciudadanía y comunicación social y cómo regulan la concentración de la propiedad mediática. Se realiza el contraste entre ambas legislaciones al considerarlas como dos casos radicalmente opuestos.
\end{abstract}

Palabras clave: sistema mediático, leyes de medio, espacio radio-electrónico.

\section{Media Laws in Chile and Argentina: So Close Yet So Far}

\begin{abstract}
This article exposes a comparative research between the Chilean media laws and the new Argentinian media law. Our objective is to analyse how this regulations consider the principles of diversity, how they understand the ties between communication and the community and if they include ownership limits. Both cases are chosen because they are considered radically opposed.
\end{abstract}

Keywords: media system; media laws, radio-electronic spectrum.

\section{Referencia normalizada}

SANTANDER, Pedro (2013): “Leyes de medios de Chile y Argentina: tan cerca tan lejos". Estudios sobre el Mensaje Periodístico. Vol. 19, Núm. 2 (julio-diciembre), págs.: 889-905. Madrid, Servicio de Publicaciones de la Universidad Complutense.

Sumario: 1. Introducción. 2. Chile y Argentina, similitudes y diferencias en lo político-comunicacional. 3. Metodología. 4. Análisis de legislación comparado; 4.1. Análisis de legislación comparado: pluralismo y diversidad; 4.1.1. Diversidad en los tipos de medios en Chile; 4.1.1.1. Medios privados; 4.1.1.2. Medios públicos; 4.1.1.3. Medios comunitarios; 4.1.2. Diversidad en los tipos de medios en Argentina; 4.1.2.1. Medios privados; 4.1.2.2. Medios públicos en Argentina; 4.1.2.3. Medios comunitarios; 4.2. Análisis legislativo comparado: diversidad y límites en la estructura de la propiedad mediática. 5. Relación comunidad-comunicación. 6. Discusión final. 7. Anexo: cuadro comparativo. 8. Referencias.

\section{Introducción}

Observamos casos en la historia que nos muestran que en ciertos contextos históricos la modificación de leyes simples es mucho más resistida por los grupos de poder que, por ejemplo, un cambio constitucional. Esto sucede cuando se considera que estos cambios de leyes pueden tener una importante incidencia sobre el campo del poder (Bourdieu, 1997). Como señala Gargarella (2010), los cambios jurídicos, pueden tener efectos en la estructura de poderes de una sociedad. Es lo que actualmente ocurre, a nuestro entender, con las leyes de medios de Sudamérica, donde en varios países se están efectuando cambios legales a leyes que organizan dogmáticamente, es decir, en relación con los derechos, el funcionamiento de los medios. Esto en un contexto de gran polarización y de fuertes debates para impedir o acelerar su aprobación. 
Modificar disposiciones legales que regulan la estructura mediática de una nación no es una cuestión inocua. Por ejemplo, una estructura medial cerrada y concentrada tanto en su propiedad como en lo discursivo, establece un contacto con la audiencia distinto a uno menos concentrado y más pluralista. El proceso comunicativo puede ser más lineal y conceptualizar a los receptores como espectadores y consumidores, $\mathrm{o}$, por el contrario, ser menos asimétrico y hacer esfuerzos por involucrar al público en dicho proceso. En ese sentido, sostenemos que cuando se norma la regulación jurídica de los medios de comunicación en un país, se configura, asimismo, la relación entre comunicación social y sociedad, por lo mismo, hablamos de una discusión donde asuntos como pluralismo, diversidad, libertad de expresión e información, etc. cobran la mayor de las importancias.

Considerando lo anterior, el objetivo de nuestra investigación es analizar comparativamente las leyes de medios chilena y argentina, para describir cómo estos cuerpos legales consideran los principios de pluralismo y diversidad y cómo norman y entienden la relación entre ciudadanía y comunicación social. Para ello realizaremos un estudio comparado de las leyes que regulan la actividad radiofónica y audiovisual, considerando que tanto la radio como la televisión deben usar para su funcionamiento un recurso público (espacio radioelectrónico), no así la prensa escrita que es, fundamentalmente, una actividad ligada al mundo privado. Además, se trata, por lejos, de los medios más consumidos por la población ${ }^{1}$.

\section{Chile y Argentina, similitudes y diferencias en lo político-comunicacional}

En relación con su historia política reciente, en ambos países ocurrieron golpes de Estado que contaron con el apoyo activo del gobierno estadounidense, instaurándose dictaduras militares en las décadas de los 70 y los 80 , con graves violaciones a los derechos humanos, y, por supuesto, con un férreo control sobre los medios.

Durante estos gobiernos comienzan reformas económicas orientadas a reestructurar completamente los modelos de desarrollo. Junto con la represión política y la desmovilización de los actores sociales, se inician procesos de apertura comercial, financiera y las privatizaciones de las empresas del Estado. Las transiciones democráticas no cambiaron dicha orientación político-económica. Por el contrario, con la llegada de los gobiernos democráticos ocurre una consolidación del neoliberalismo profundizándose las transformaciones estructurales iniciadas por los gobiernos militares. Se produce en la región "un escenario sin trabas de imposición del proyecto neoliberal" (Estay, 2012), gracias a gobiernos que privilegian en sus diseños la estabilidad macroeconómica con políticas de disciplina fiscal y control inflacionario. El Estado se concibe en un rol subsidiario, priorizándose el sector exportador y la inversión privada, especialmente en la explotación de los recursos naturales. Lo anterior se consolida en Argentina durante los 2 gobiernos neopopulistas de Carlos Menem (Ellner, 2004) ${ }^{2}$, y en Chile con los gobiernos de centro-izquierda de la Concertación, cuyo eje es la alianza entre socialistas y democristianos.

1 En América Latina la penetración de Internet es aún relativamente limitada, aunque creciente. De acuerdo a los datos provistos por Internet World Stats (dic. 2011), el promedio de penetración es del $32.1 \%$ de su población.

2 También llamados neoconservadores (Alegre, 2012: 43) 
En este período observamos también en el campo mediático similitudes en ambos lados de la cordillera: se conforman multimedios nacionales y luego conglomerados transnacionales.

En Chile el campo mediático muestra una altísima concentración, tanto en el ámbito de la prensa escrita, la radial como la audiovisual, y una estructura oligopólica, tanto desde la perspectiva de la propiedad como de la inversión publicitaria (Corrales y Sandoval, 2005; Mastrini, etc.). En la prensa hay una situación duopólica: dos cadenas concentran más del 90\% de los diarios y de los lectores; el mercado radial es oligopólico: 4 consorcios concentran el 70\% del mercado radial, solo el grupo español Prisa acapara 220 frecuencias, que corresponden al 30\% del mercado y al 50\% de la inversión publicitaria; cuatro canales de televisión abierta se reparten el 95\% de la audiencia nacional y de la torta publicitaria, y dos compañías de telefonía concentran el total del mercado de tv por suscripción.

En Argentina el Grupo Clarín es la principal corporación multimedial de ese país, concentra el 31 por ciento de la circulación de periódicos, el $28 \%$ de la audiencia de la televisión abierta (Becerra y Mastrini, 2009) y es propietario de los siete principales sitios de Internet en relación con el número de visitas (Igarza, 2010).

Otra similitud que han compartido en lo comunicacional es que se han mantenido vigentes las leyes de medios aprobadas por las dictaduras. Si bien Argentina recupera la democracia en 1983, no fue sino hasta el año 2009 que se reemplazó el Decreto Ley ${ }^{\circ} 22.285$ promulgado por los militares en 1980, por la Ley de Servicios de Comunicación Audiovisual. En Chile hasta hoy rige la Ley 18.838 que crea el Consejo Nacional de Televisión (CNTV), órgano que regula el funcionamiento de la televisión, y que fue aprobada por los militares en 1989.

A partir de 2009 comienzan las diferencias, éstas, por supuesto, no se limitan sólo a lo comunicacional. Antes bien, los cambios en lo comunicacional parecen dar cuenta de cambios en lo económico-político. Según Espinosa (2012: 126), después de los gobiernos desarrollistas de los ' 50 y ' 60 , en los '70 se evoluciona en Argentina “de dictaduras militares neoliberales, a gobiernos civiles neoliberales, a gobiernos civiles neodesarrollistas". En Chile ocurre lo mismo, sólo que se llega hasta la etapa neoliberal; en este país hasta hoy se mantiene el proyecto neoliberal, con un régimen de incentivos extremos al gran capital y una profundización de la transnacionalización y desnacionalización de la economía (Varesi, 2012). En Argentina se pasa a la última etapa, la de los gobiernos neodesarrollistas, a partir de las presidencias de Néstor Kirchner y Cristina Fernández. Se reorienta el modelo de acumulación que, alejándose del dogma neoliberal, apuesta por el capitalismo productivo nacional, manteniendo, eso sí, los incentivos a la inversión extranjera, especialmente en la explotación de los recursos naturales, aunque ahora con una fuerte incidencia del Estado en el despliegue de estrategias de intervención económicas y políticas, en alianza con amplios sectores populares movilizados.

En este contexto, el año 2009 se aprueba la Ley de Servicios de Comunicación Audiovisual 26.522, también conocida como Ley de Medios de Argentina. 


\section{Metodología}

Para proceder analíticamente con nuestro objetivo de investigación, hemos definido tres categorías comparativas. La elección de éstas está guiada por la legislación internacional que existe en torno a las políticas de comunicación:

- La Declaración de Principios de Libertad de Expresión de la Comisión Interamericana de Derechos Humanos (2000)

- Los Indicadores de Desarrollo Mediático de las NU (2008)

- La Declaración Conjunta sobre Diversidad en la Radiodifusión (2007)

- El estudio comparativo de legislaciones de trece países que realizó de la UNESCO (2003)

Las categorías comparativas que guiarán el análisis son:

1) Descripción general y génesis de las leyes: contexto y modo legislativo en que se generaron.

2) Pluralismo y diversidad: ésta categoría se analiza en dos subcategorías:

- Tipos de medios: públicos, comerciales, comunitarios.

- Diversidad y límites a la estructura de la propiedad mediática.

Establecimos estas dos subcategorías, ya que los textos fuente consultados coinciden en que el pluralismo y la diversidad comunicacional se logra si hay diversidad en los tipos de medios y en la estructura de propiedad. En su declaración conjunta sobre Libertad de Expresión, los relatores señalan que "la naturaleza compleja de la diversidad incluye la diversidad de medios de comunicación, de propiedad de los medios así como la diversidad de contenido". Asimismo, al explicar los indicadores que proponen las NU (2008) para medir libertad de expresión y de desarrollo mediático, se señala la importancia que los Estados "promuevan activamente el desarrollo del sector mediático de manera que evite una indebida concentración y asegure la pluralidad y transparencia de la propiedad y el contenido entre los medios públicos, privados y comunitarios" (NU: 7).

3) Relación comunidad-comunicación: interesa conocer cómo conciben las legislaciones el vínculo entre sociedad civil y comunicación social, si la comunidad tiene posibilidad de participar en la regulación de la comunicación, si tiene incidencia en toma de decisiones, cómo se concibe a los grupos minoritarios en el proceso comunicacional, etc.

\section{Análisis de legislación comparado}

En el caso de Chile, son cuatro las leyes que regulan los medios que para su funcionamiento requieren solicitar al Estado concesiones:

a) La Ley General de Telecomunicaciones (1982), $\mathrm{n}^{\circ} 18.168$

b) La Ley que crea el Consejo Nacional de Televisión, CNTV, (1989), nº 18.838 .

c) Ley que crea la Empresa Televisión Nacional de Chile (1992), $\mathrm{n}^{\circ}$ 19.132.

d) La Ley de Servicios de Radiodifusión Comunitaria (2010), no 20.433.

Dos de las cuatro leyes fueron promulgadas durante la dictadura (1973-1990), son además las de mayor alcance regulatorio. La de 1982, ley que norma la administración 
del espacio radioeléctrico, regula "toda la transmisión de imágenes, sonidos e información de cualquier naturaleza por los sistemas electromagnéticos" (art. 1). La de 1989 regula la actividad televisiva general. El CNTV es la autoridad de aplicación, correspondiéndole "velar por el correcto funcionamiento de los servicios de televisión" (art. 1); además "otorga, modifica o declara el término de las concesiones de servicios de radiodifusión" (art.12).

Las otras dos leyes son específicas, la de 1992 se refiere al funcionamiento del único medio que posee el Estado, Televisión Nacional de Chile y la Ley de Radiodifusión Comunitaria (2010) establece la normativa para las radios comunitarias.

Como vemos, existe una ley que regula las telecomunicaciones, otra la actividad televisiva, otra las radios comunitarias y una última que norma al canal del Estado. La situación en Argentina es distinta, la Ley de Servicios de Comunicación Audiovisual (2009) reúne en su texto toda la reglamentación relacionada con la televisión abierta y paga, con la radiodifusión, con los medios comunitarios, con los medios públicos $\mathrm{y}$, en general, todo lo referente a la administración y gestión del espacio radioelectrónico. También incluye la convergencia digital entre televisión, telefonía e Internet.

En cuanto a su génesis, nos interesa describir el modo en que las leyes se generaron y los procedimientos metodológicos que se usaron para su elaboración.

En el caso de Chile dos de las cuatro leyes en cuestión -que además tienen mayor alcance pragmático- se promulgaron durante la dictadura. Las otras dos, al iniciarse el proceso de transición a la democracia. En ninguno de los casos, hubo debate con la sociedad civil.

Una de las características distintivas de la ley argentina es el proceso de discusión cívico-política que implicó. El punto de partida fue la elaboración que en 2004 realizó la Coalición por una Radiodifusión Democrática (CRD) -organización integrada por unas 300 organizaciones sociales, sindicales, universitarias y medios comunitariosde los "21 Puntos para una Radiodifusión Democrática". Ese mismo año la CRD, entregó su propuesta al presidente Néstor Kirchner. Los "21 Puntos" fueron la base del proyecto que en 2009 mandó la presidenta Cristina Fernández al Congreso. El proyecto quedó a disposición de cualquier interesado a través de Internet, con una dirección electrónica especialmente habilitada para formular comentarios; entre marzo y septiembre se recibieron cientos de correos electrónicos opinando al respecto. Paralelamente se realizaron 24 "Foros Participativos de Consulta Pública", además de 80 debates ciudadanos. Todo ello resultó en la recepción de más de mil trescientas propuestas de modificación del proyecto original (Bulla, 2011). Finalmente, el año 2009, la ley fue aprobada por ambas cámaras, en medio de una fuerte controversia política entre oposición y oficialismo. Según Mauersberger (2012: 590) estos foros movilizaron a una gran parte de la sociedad y aseguraron una base de apoyo público para un tópico controversial y "el exitoso trámite legislativo sólo puede ser entendido considerando el poder organizativo de los movimientos que lo respaldaron, el potente marco transformador de la reforma y las relaciones en transformación entre Estado y medios".

Cabe señalar que el texto definitivo emplea la modalidad de ley anotada, consignándose tanto la legislación internacional comparada que inspira a los criterios que se 
incluyen, como las modificaciones que se hicieron al proyecto original y las organizaciones sociales que las propusieron. Es así como el texto contiene 109 notas al pie de página que dan cuenta de ello.

\subsection{Análisis de legislación comparado: pluralismo y diversidad}

Cuando hablamos de pluralismo en el sistema mediático de un país, y siguiendo la legislación y las recomendaciones internacionales, nos referimos a la existencia de diversidad en los tipos de medios, es decir, presencia de medios comerciales (privados con fines de lucro), comunitarios (privados sin fines de lucro) y públicos. La Unesco (2008) recomienda específicamente la existencia de estos tres tipos de medios y considera dicha mezcla como un indicador clave para el desarrollo y fortalecimiento de la democracia y para establecer lo que se denomina una ecología mediática sana en un país:

En general, lo mejor es lograr una diversidad de medios públicos, comunitarios y particulares mediante medidas legales, financieras y administrativas, con disposiciones específicas para alentar a los medios comunitarios y, en el sector de radio y televisión, asignar justa y equitativamente el espectro (Unesco: 2008: 26).

Para que ello ocurra el sistema regulador debería asegurar un acceso equitativo al espectro de frecuencias y los procesos de toma de decisiones sobre la asignación de frecuencias deberían ser abiertos y participativos; asimismo, los procesos de asignación deberían ser vigilados por "un órgano libre de interferencia o control político o comercial" (Unesco, 2008: 27). En un sentido similar, la Corte Interamericana de DDHH (2011: 387) recomienda explícitamente a los Estados "adoptar una legislación que asegure criterios transparentes, públicos y equitativos para la asignación de frecuencias radioeléctricas y del nuevo dividendo digital. Esta legislación debe tomar en cuenta la situación actual de concentración en la propiedad de los medios de comunicación".

En cuanto al tercer sector de la comunicación, la CIDH (2011: 387), recomienda a los Estados "legislar en materia de radiodifusión comunitaria, de manera que se destine una parte equitativa del espectro y del dividendo digital a las radios y canales comunitarios".

\subsubsection{Diversidad en los tipos de medios en Chile 4.1.1.1. Medios privados}

El sector privado en Chile no consigue autorización legal para operar canales de televisión sino hasta 1989, antes, la televisión estaba exclusivamente en manos de las universidades y del Estado. A mediados de los '70 el gobierno militar comienza a flexibilizar el acceso de los privados a la televisión con una paulatina liberalización en el ingreso de publicidad. En 1977 elimina las restricciones que existían para la contratación de publicidad, y los capitales privados pasan a tener un rol cada vez más relevante en el financiamiento del medio (Corrales y Sandoval, 2005). Este proceso llega a su punto culmine con la autorización para la creación de estaciones de televisión privadas, a través de la ley 18.838 de 1989. Se instaura el principio de acceso 
abierto de los privados a la propiedad de las señales de televisión mediante un sistema de concesión de duración indefinida. Así se abre la posibilidad para que particulares sean propietarios de canales, y se realiza en la práctica una privatización de un recurso público y finito como es el espacio radioelectrónico, con la entrega de concesiones indefinidas.

El CNTV inicia en 1989 el proceso de adjudicación de las primeras concesiones privadas en la banda VHF. Las dos primeras estaciones privadas autorizadas fueron Canal 9 -adquirido por un grupo económico nacional ligado al sector naviero e industrial- y Canal 4, adjudicado a un grupo económico nacional ligado al sector bancario. Así, iniciándose la transición, la estructura del sistema mediático chileno comienza a ser "completamente dominada por el sector privado" (Tironi y Sunkel, 1993: 240).

En 1992 se modifica esta ley, poniéndole límites a la entrega de las concesiones al sector privado, estableciendo un plazo de 25 años para todas las frecuencias post 1992, pero manteniendo el carácter de indefinidas para las anteriores, configurándose así un sistema mixto ${ }^{3}$.

Hoy, después de 23 años de democracia, el sistema televisivo se caracteriza por la privatización de la industria. De los tres canales universitarios que existían cuando finaliza la dictadura (1990), dos pertenecen a grupos económicos. Canal 13, que era de la Universidad Católica de Chile, es propiedad del principal grupo económico del país, el grupo Lucksic; Canal 11, que pertenecía a la Universidad de Chile, fue adquirido por el actual presidente de la República, Sebastián Piñera, quien lo vendió en 2011 al grupo transnacional Time Warner; todos gozan del uso indefinido de la frecuencia.

\subsubsection{Medios públicos}

En Chile fueron las universidades y el Estado las grandes impulsoras de la televisión. A partir de los '60 se configura el denominado sistema "universitario-estatal", el que tendrá una formulación jurídica en 1970, con la Ley General de Televisión (Tironi Y Sunkel, 1993). A través de ella se crea Televisión Nacional de Chile (TVN) que entrega al Estado la explotación del medio, como único autorizado para extenderse hacia todo el territorio. A partir del golpe de 1973 se introdujeron profundas transformaciones. La Junta Militar suprimió las estructuras pluralistas de la televisión estatal e intervino las universidades con rectores-delegados. En 1974, se establece que las dependencias de TVN se trasladan desde el Ministerio de Educación a la Secretaría General de Gobierno, repartición encargada de la comunicación política del gobierno y de la cual dependía el organismo encargado de la censura y control de la prensa, la Dirección Nacional de Comunicación Social (DINACOS).

Esta situación cambia en 1992, cuando el Congreso promulga la Ley 19.132 que crea la empresa Televisión Nacional del Chile. Dos son aquí los hechos destacables. En primer lugar, el régimen económico que se le impone al canal público. Tal como

${ }^{3}$ Esta situación que se mantiene hasta el día de hoy, podría experimentar cambios con el proyecto de Televisión Digital que se está discutiendo en el Congreso desde 2008 y que propone licencias de 20 años para todos los actores. 
señala el art. 24, a TVN "no se aplicarán las normas de régimen y administración económica que rigen a las empresas del Estado". El art. 25 agrega, "TVN, en caso alguno, podrá obtener financiamientos, créditos, aportes, subsidios, fianzas o garantías del Estado o de cualesquiera de sus organismos, entidades o empresas, sino en los casos en que ello fuere posible para el sector privado y en iguales condiciones". Es decir, el canal del Estado debe competir en Chile con los demás canales privados en igualdad de condiciones y buscar su autofinanciamiento en el mercado.

En segundo lugar, destaca la administración que esta ley impone a TVN en relación con la composición y designación de su directorio. De sus siete miembros uno es designado por el Presidente de la República y será el presidente del directorio, los otros seis son propuestos por el mandatario al senado. El senado se pronuncia acerca de esta propuesta "en sesión secreta especialmente convocada al efecto" (art. 4). En cuanto a la participación de los trabajadores del canal en el directorio, la ley señala que "el Directorio estará integrado por un representante de los trabajadores, el cual sólo tendrá derecho a voz" (art. 4).

Radioemisoras públicas no existen en Chile. La única que funcionó un tiempo fue Radio Nacional de Chile (1974-1993). Hasta el golpe de estado de 1973 era Radio Corporación, pertenecía al Partido Socialista y fue una de las dos emisoras que transmitieron el último discurso del Presidente Salvador Allende. Luego fue expropiada por los militares y convertida en Radio Nacional, la emisora oficial de la dictadura. En 1993 fue licitada y privatizada.

\subsubsection{Medios comunitarios}

Al igual que en la mayoría de los países latinoamericanos, los medios comunitarios en Chile han transitado entre la precariedad y la clandestinidad. La legislación, a través de la Ley de Telecomunicaciones, establecía mecanismos discriminatorios contra estos medios pues no se les otorgaban concesiones por más de cinco años, se les ponía límites técnicos a su capacidad de emisiónEsta situación discriminatoria se mantuvo sin muchas variaciones hasta el año 2010. Entonces, el congreso aprobó la "Ley que crea los servicios de radiodifusión comunitaria"; esta norma da existencia legal a radios comunitarias. Sin bien enuncia en su artículo $2^{\circ}$ el "acceso equitativo a las concesiones de todos los sectores sociales", entrega, en promedio, sólo un $2 \%$ de la banda de frecuencia modulada (FM) a las radios comunitarias, tanto analógicas como digital (art.3). En cuanto a restricciones técnicas, establece para ellas "una potencia máxima de 25 watts, con una altura de antena de hasta dieciocho metros" y el plazo de las concesiones es de diez años (art.11). Esta norma establece límites a la propiedad: "no se podrá ser titular ni explotar a cualquier título más de una concesión de Servicios Comunitarios y Ciudadanos de Radiodifusión de Libre Recepción" (art. 9). Respecto del financiamiento, se permite publicidad, aunque con restricciones, al señalar que las radios "podrán difundir menciones comerciales o de servicios que se encuentren en su zona de servicio. Se entenderá por menciones comerciales el saludo o agradecimiento a una entidad, empresa, establecimiento o local comercial, indicando únicamente su nombre y dirección", (art. 13), es decir, la mención comercial la deben hacer los locutores. En relación con restricciones al contenido, llama la atención que 
el art. 13 señala que estos medios "en ningún caso podrán emitir propaganda electoral o política".

No existe legislación específica para la televisión comunitaria. Frente a situaciones como esas, la Unesco señala que "en algunos países, no hay ni normas específicas sobre los medios comunitarios, ni reconocimiento legal del servicio cuando exista. En tal caso, los medios comunitarios sin fines de lucro se ven obligados a operar dentro del marco jurídico de los medios particulares, sometidos a las fuerzas del mercado"(Unesco: 2008: 25).

\subsubsection{Diversidad en los tipos de medios en Argentina}

Desde el retorno de la democracia el campo mediático argentino ha tenido en común con el chileno el funcionamiento precario y a menudo ilegal de los medios comunitarios, la debilidad de su sistema público de medios y una creciente privatización y transnacionalización de su estructura medial. Como señalábamos, las diferencias comienzan el 2009 con la nueva Ley de Medios.

\subsubsection{Medios privados}

El sistema de medios de Argentina, al igual que en Chile, experimentó durante los años ' 80 y ' 90 un proceso que comenzó con la conformación de multimedios nacionales y evolucionó hacia la constitución de conglomerados transnacionales. Como señala de Charras (2011:68), "la década del '90 se caracterizó en Argentina por un proceso de compras y fusiones incomparable con épocas anteriores, y en la cual la legislación se caracterizó por ser un mero trámite a posteriori de adaptaciones normativas a las necesidades del mercado".

El panorama del sistema audiovisual argentino es de extrema concentración. Por ejemplo, el Grupo Clarín posee el 55\% del servicio pago de televisión en el país tras un proceso de fusiones empresariales, y acumula 191 licencias, cuando el máximo permitido por ley, desde 1999, es de 24. Clarín es el grupo mediático más importante de Argentina, combinando integración horizontal y vertical, y asociaciones con consorcios transnacionales como Goldman Sachs y Atlantida (Sel, 2010). En cuanto a la televisilibre recepción, el grupo Telefónica es el mayor operador del país, posee los canales 9 y 11, además de radios, medios gráficos, productoras audiovisuales y telefonía móvil (Sel, 2010).

La nueva Ley de Medios (26.522) cambia, legislativamente, esta situación. En términos generales la nueva ley procura un tratamiento igualitario entre los medios del sector público, el privado y el comunitario, poniendo fin a los mecanismos de discriminaciones al eliminar las limitaciones técnicas, de frecuencia, de licencias o de financiamiento y al tratar por igual a los tres actores. La ley reconoce (art.2) la existencia de los tres tipos de medios, "la explotación de los servicios de comunicación audiovisual podrá ser efectuada por prestadores de gestión estatal, de gestión privada con fines de lucro y de gestión privada sin fines de lucro, los que deberán tener capacidad de operar y tener acceso equitativo a todas las plataformas de transmisión disponibles".

A este reconocimiento legal -que es inédito en Argentina- se suma una disposición que establece un tratamiento equitativo en el acceso a las frecuencias. En ese sentido, 
el art. 89 otorga y reserva por partes iguales un 33\% del espectro radioelectrónico a los medios privados, a los públicos y a los comunitarios ${ }^{4}$.

Hasta ahora, los medios privados argentinos tenían un acceso preferente a las concesiones y a la renovación de las mismas, con una duración de 15 años. Con la nueva ley el período de uso y de prórroga es el mismo para todos, ya sea una radio comunitaria de una provincia alejada o un gran canal con cabecera en la capital, duran 10 años y se pueden renovar por 10 años más, por una vez.

Por otro lado, la ley contempla límites a la concentración de licencias para todos. Cuando se trate de radiodifusión sonora o de televisión ya sea abierta o de pago, un mismo actor no podrá tener más de diez licencias (art.45); además, "la multiplicidad de licencias en ningún caso podrá implicar la posibilidad de prestar servicios a más del 35 por ciento del total nacional de habitantes o de abonados". También se impide que las compañías telefónicas brinden servicios de televisión por cable. Esta disposición antimonopólica tiene un carácter retroactivo, al señalar su art. 161 una norma de adecuación, "los titulares de licencias de los servicios y registros regulados por esta ley [...] o las personas jurídicas que al momento de entrada en vigencia de esta ley fueran titulares de una cantidad mayor de licencias, o con una composición societaria diferente a la permitida, deberán ajustarse a las disposiciones de la presente en un plazo no mayor a UN (1) año desde que la Autoridad de Aplicación establezca los mecanismos de transición. Vencido dicho plazo improrrogable serán aplicables las medidas que al incumplimiento -en cada caso- correspondiesen".

\subsubsection{Medios públicos en Argentina}

Los medios públicos argentinos comienzan a desarrollarse en los años '30 con la radio. A mediados del siglo 20, coincidiendo con la llegada del peronismo al Gobierno, el Estado asume una rol protagónico, adquiriendo tres grandes cadenas de radioemisoras, creando la Agencia de Noticias Telenoticiosas Americana (TELAM) y la señal pública Canal 7 que se inaugura trasmitiendo un discurso de Eva Perón en 1951. Fue en esa época que se aprueba la primera ley de medios promulgada en democracia (Verano, 2011). Sin embargo, en medio de los vaivenes políticos, el sistema público de medios, luego de un fuerte impulso durante el período peronista, comienza a debilitarse y, en paralelo, a fortalecerse el privado. Con la promulgación, en 1980, de la Ley de Radiodifusión de la dictadura que prohibía los medios comunitarios y restringía el rol de los medios públicos a "proveer servicios de radiodifusión cuando no lo preste la actividad privada", se inicia una política oficial de privatización de los medios audiovisuales y un languidecimiento de los públicos (Verano, 2011).

La actual ley se plantea "fortalecer los medios públicos, sacándolos del espacio subsidiario al que las reglas del mercado lo habían relegado" (Baranchuk, 2011:17) y, en base a estudios de legislación comparada de Australia, Alemania, Canadá, Francia, España y Chile, se crea Radio y Televisión Argentina Sociedad del Estado (RTA S.E.). Esta sociedad "tiene a su cargo la administración, operación, desarrollo y explotación

4 En América Latina, también Uruguay y Bolivia han adoptado una norma muy similar que reserva equitativamente el espacio radioelectrónico a los tres tipos de medios. 
de los servicios de radiodifusión sonora y televisiva del Estado Nacional" (art.119). Incorpora diversas frecuencias nacionales y locales; su grilla debe incluir un mínimo del $60 \%$ de programación propia y un $20 \%$ de producciones independientes.

La estructura de RTA S.E. considera dos entes de gestión. En primer lugar, un Directorio conformado por siete integrantes. El Ejecutivo designa directamente a dos, los demás por el Congreso, la ley obliga a que la segunda y la tercera minoría parlamentaria estén representadas. El directorio dirige RTA S.E., aprueba las programaciones, los presupuestos anuales, etc.

En segundo lugar, se establece un Consejo Consultivo de Medios Públicos, el que "ejercerá el control social del cumplimiento de los objetivos de la presente ley" (art. 124). Diecisiete personas, designadas por el poder ejecutivo, lo integran. Deben ser representativas de la sociedad civil, por ejemplo, dos de las facultades de comunicación de las universidades nacionales, tres de sindicatos de RTA S.E., dos de ONG's de Derechos Humanos, una persona será propuesta por los pueblos originarios, etc. Las reuniones de este Consejo serán públicas y entre sus competencias figura (art. 130) "convocar a audiencias públicas para evaluar la programación, los contenidos y el funcionamiento de RTA S.E.", así como "convocar semestralmente a los integrantes del Directorio de RTA S.E. a efectos de recibir un informe de gestión".

A diferencia de Televisión Nacional de Chile los medios que forman parte de RTA S.E. no deben autofinanciarse. Si bien la publicidad forma parte de las estrategias de financiamiento, también se cuenta con el apoyo del Estado a través de asignaciones presupuestarias contempladas anualmente en la Ley de Presupuesto Nacional y un $35 \%$ del impuesto que esta nueva Ley de Medios contempla 5 .

\subsubsection{Medios comunitarios}

La Ley de Medios otorga a los medios comunitarios un reconocimiento legal del que carecían y los mismos derechos que tienen los comerciales. Las barreras de entrada, así como las posibilidades de asignación y de renovación de concesiones se igualan. Se eliminan los límites de potencia, de frecuencias o la existencia de plazos de renovación diferentes al del sector comercial. Se establece una reserva de banda para estos medios de un 33\% del espectro radioelectrónico (art.89, letra f) ${ }^{6}$. También una reserva

5 De acuerdo a la ley 26.522 (art. 85) “todos los titulares de servicios de comunicación audiovisual en Argentina tributarán un gravamen proporcional al monto de la facturación bruta correspondiente a la comercialización de publicidad tradicional y no tradicional, programas, señales, contenidos, abonos y todo otro concepto derivado de la explotación de los servicios contemplados en la presente ley". Este cobro de tasa fiscal sobre publicidad se inspira en el ejemplo del Fonds de Soutien a l'expression Radiophonique, del Ministerio de Cultura francés.

6 En la nota aclaratoria de este artículo, al pie de página, se explica que "las previsiones vinculadas a la reserva de espectro radioeléctrico se apoyan en la necesidad de la existencia de las tres franjas de operadores de servicios, de conformidad a las recomendaciones de la Relatoría de Libertad de Expresión ya planteadas con anterioridad. Por ello, se preserva un porcentaje para las entidades sin fines de lucro que admita su desarrollo, al igual que para el sector comercial privado". 
de frecuencias para los pueblos originarios, "UNA frecuencia de AM, UNA frecuencia de FM y UNA frecuencia de televisión para los pueblos originarios en las localidades donde cada pueblo esté asentado". mayor que para las demás radios comunitarias: 30 watts v/s 25 watts?

\subsection{Análisis legislativo comparado: diversidad y límites en la estructura de la propiedad mediática}

En Chile prácticamente no existen límites a la propiedad privada de los medios comerciales, sólo de los comunitarios. El panorama es de alta concentración, tanto en la prensa escrita (duopolio), como en la radial y en la audiovisual (escenario oligopólico). De hecho, cuando se discutió -desde 1993 a 2001- en el Congreso la "Ley sobre Libertades de Opinión e Información y Ejercicio del Periodismo ( $\left.{ }^{\circ} 19.733\right)$, el punto más controvertido fue el de la propiedad. El proyecto original proponía límites para favorecer el pluralismo. Se prohibía, "el control de más del $30 \%$ del mercado informativo nacional en manos de una persona natural o jurídica, sola o asociada con otra u otras", y "el dominio de dos o más tipos diversos de medios de comunicación social en un mismo mercado, por una persona natural o jurídica". Pero los parlamentarios de derecha, con mayoría en el Senado, eliminaron este punto, argumentando que sería inconstitucional y que la verdadera regulación de la propiedad debe quedar exclusivamente en manos del mercado (Hevia, 2001).

Por otro lado, en relación a las concesiones para los canales de televisión, éstos por ley no pueden vender sus concesiones ya que las frecuencias pertenecen al Estado, pero sí está permitido que se produzcan cambios en la composición accionaria de las sociedades, en tal caso, la única obligación que existe es la de informar al CNTV. Es lo que justamente ha ocurrido con los canales que gozan de un régimen de concesiones indefinidas (pre 1992) y que, como Canal 11, pasaron de manos de la Universidad de Chile, a la del actual presidente Sebastián Piñera y luego a la transnacional Time Warner.

El único mecanismo que limita relativamente la propiedad mediática privada en Chile es el llamado principio de reciprocidad, en el ámbito radial. Este implica que "las concesiones radiales solicitadas por personas jurídicas con participación de capital extranjero superior al diez por ciento, sólo podrán otorgarse si se acredita, previamente, que en su país de origen se otorga a los chilenos derechos y obligaciones similares a las condiciones de que gozarán estos solicitantes en Chile". Sin embargo, el caso del consorcio español Prisa, que concentra más del $30 \%$ de las radiofrecuencias de libre recepción FM en Chile, demuestra que no se cumple con esta disposición.

En el caso de la Ley de Medios de Argentina ésta tiene un claro carácter antimonopólico. Se restringe el número de licencias por actor, tanto en televisión como en radio, se regula la propiedad horizontal y vertical, y se prohíbe que compañías telefónicas brinden servicios de televisión por cable. Igualmente (art. 45), cuando el pres-

7 En el caso de Chile, la Ley de Radiodifusión Comunitaria permite para los pueblos originarios un límite de potencia 5 watts mayor que para el resto. 
tador del servicio sea una sociedad comercial, ésta deberá tener un capital de origen nacional, permitiéndose la participación de capital extranjero sólo de hasta un máximo del 30\%. Esta regulación también se extiende a la actividad publicitaria. En ese sentido, se prohíbe expresamente la "publicidad subliminal" (art. 71, letra f), el contenido discriminatorio (étnico, de género o clasista) y se fijan tiempos máximo: 14 minutos de publicidad por hora en las radios, y 12 en la televisión abierta y entre 6 y 8 minutos en la tv paga.

\section{Relación comunidad - comunicación}

El modo en que un sistema de medios se estructura y se regula, influye en la relación que se establece entre medios y audiencia. El sistema de medios tradicionales ha sido frecuentemente descrito por la literatura especializada como lineal y con poco interés en abrir canales regulares de participación con los ciudadanos. Thompson (1998), por ejemplo, habla de un sistema "estructuralmente asimétrico", Fairclough (1997) conceptualiza esta relación como "cuasi interacción mediada", Bourdieu (1998) describe los medios como esencialmente autorreferenciales. Esta estructura mediática que implica un poder unidireccional de pocos sobre la creación y circulación de discursos que serán consumidos por muchos, es un fenómeno que en los últimos años está siendo desafiado. Una manera es la Web 2.0. (Bowman y Willis, 2003; Meraz, 2011), otra son las regulaciones que limitan la concentración mediática y crean instancias de toma de decisión para la ciudadanía en el proceso comunicacional. Según postulamos, en Argentina, así como en otros países de Sudamérica, se están discutiendo nuevas regulaciones que consideran estos puntos con el fin de enfrentar la asimetría comunicacional que los medios han configurado.

La posibilidad de que los ciudadanos formen parte activa de los procesos de comunicación social tiene varias dimensiones. Una primera es que las personas tengan acceso a la oferta comunicacional. Igualmente importante es el acceso con voz propia a la comunicación masiva. En ese sentido, la incorporación legal de las organizaciones de la sociedad civil sin fines de lucro al sistema mediático, marca la diferencia.

Otra instancia crucial y profundamente democrática es la participación de la ciudadanía en la discusión y elaboración de las leyes. Es lo que ocurrió en Argentina con la nueva ley. No es un caso aislado en el subcontinente, se trata, antes bien, de una tendencia de los últimos años en Sudamérica (Kaplún 2010, Lemos, 2010).

Un tercer punto importante es la incidencia efectiva que la ciudadanía puede tener sobre la implementación de las políticas comunicacionales. Para analizar comparativamente este punto es interesante comparar los grados de participación que tiene la sociedad civil en los órganos oficiales de aplicación de las normativas. En Argentina, el organismo de aplicación es la Autoridad Federal de Servicios de Comunicación Audiovisual (AFSCA); en Chile el Consejo Nacional de Televisión (CNTV).

En cuanto a su composición, la AFSCA está formada por un directorio de siete miembros. El presidente y otro más son nombrados directamente por el Ejecutivo, tres por el Congreso, los otros dos directores son propuestos por el Consejo Federal de Comunicación (ver más abajo), uno debe ser obligatoriamente académico de alguna carrera de ciencias de la comunicación. Sus nombres deben ser previamente dados a 
conocer públicamente, pudiendo así la ciudadanía manifestar su discrepancia con las candidaturas si las hubiere. Haber sido miembro del gobierno dictatorial es una de las causales de incompatibilidad para ocupar el cargo (al igual que para obtener una licencia en el espacio radioelectrónico).

En Chile el directorio del CNTV está integrado por once consejeros, sus nombres se discuten en el senado en una sesión secreta, no es obligación que alguno de sus miembros pertenezca a algún organismo de la sociedad civil y "los Consejeros deberán ser personas de relevantes méritos personales y profesionales, tales como: [...] haber sido Oficial General de alguna de las Instituciones de las Fuerzas Armadas o de Carabineros de Chile", (art. 2, letra b).

La estructura administrativa de la AFSCA incluye un órgano asesor llamado Consejo Federal de Comunicación Audiovisual que cuenta con facultades de control, asesoramiento y remoción de los miembros del directorio (Bulla, 2011), propone 2 de los 7 integrantes del directorio. El Consejo está constituido por 39 miembros. De éstos, tres representan a los medios privados de carácter comercial, tres a los medios comunitarios, uno a las universidades con carreras de comunicación, uno a los medios públicos, tres a entidades sindicales, uno a las sociedades gestoras de derechos y uno a los pueblos originarios.

Otra instancia de participación de la ciudadanía en las definiciones generales sobre el sistema de comunicación audiovisual, que, según Bulla (2011: 101), "es el nivel más alto de participación y la forma más genuina y directa para que los ciudadanos se expresen sobre el sistema", son la audiencias públicas. De acuerdo a la ley (art. 40), "las licencias serán susceptibles de prórroga por única vez, por un plazo de DIEZ años, previa celebración de audiencia pública realizada en la localidad donde se preste el servicio, de acuerdo a los principios generales del derecho público en dicha materia". Es decir, si una radio o un canal quiere prorrogar su licencia, debe someterse a una audiencia pública, donde la comunidad se pronuncia acerca del servicio que ha recibido. "Este mecanismo está inspirado en la legislación canadiense, al tomar al pie de la letra el hecho de que el espectro es patrimonio público de la humanidad, administrado por el Estado, y que no tiene dueño", (Bulla, 2012).

No existe en Chile ningún tipo de participación ni directa ni indirecta de los ciudadanos en los procesos de adjudicación de prórrogas de licencias o de control en la aplicación de la ley.

\section{Discusión final}

Existe consenso en la bibliografía especializada que la estructura mediática mundial muestra altos índices de concentración. Es a finales del siglo pasado cuando el campo mediático comienza a experimentar globalmente un acelerado proceso de concentración (Dragomir, 2007; Faingezicht, 2007; Reig, 2011). Hoy el sistema mediático, que ocupa un lugar importante en la estructura socioeconómica mundial y en la articulación global del consumo, está guiado por la búsqueda de rentabilidad permanente y ejerce in-

${ }^{8}$ Entrevista personal, Buenos Aires, 11 de abril de 2012. 
fluencia ideológica. Por lo mismo, los medios ocupan un lugar importantísimo en lo que Bourdieu (1988) denomina el campo del poder. Para ello el sistema mediático requiere mantener la seguridad jurídica para su propiedad privada. Este sistema, además de concentrado en términos económicos, también muestra una clausura discursiva, convirtiéndose así en un sistema lineal y asimétrico en su relación con la ciudadanía.

Los procesos de discusión legislativa en Sudamérica tienen lugar en contextos de cambios políticos y de cuestionamientos del camino neoliberal. Se trata de cambios legales que buscan modificar la relación entre medios y audiencia así como entre Estados y medios privados. Por lo mismo, es entendible que la mutación de la situación jurídica suscite tanta resistencia, como si se tratase de un cambio constitucional, pues el efecto pragmático de estas leyes puede ser de amplísimo alcance.

Argentina y Chile han optado por caminos distintos, están situados en los polos de un mismo eje. Chile ha permanecido en la vía neoliberal. La opción de Argentina de transitar por la vía neodesarrollista tiene su correlato comunicacional en la nueva Ley de Medios. Según Frank La Rue, relator de las NU en materia de Protección de la Libertad de Expresión, "es lo más avanzado que hay en el mundo en ley de telecomunicaciones, además, por el procedimiento que se siguió, el proceso de consulta popular, me parece que esta es una ley realmente consultada con su pueblo".

\section{Anexo: cuadro comparativo}

\begin{tabular}{|l|l|}
\hline \multicolumn{2}{|c|}{ Origen de las leyes } \\
\hline En Dictadura y en Democracia & En democracia \\
\hline $\begin{array}{l}\text { Sin participación de la ciudadanía en génesis } \\
\text { ley. }\end{array}$ & $\begin{array}{l}\text { Con alta participación de la ciudadanía en } \\
\text { génesis ley. }\end{array}$ \\
\hline
\end{tabular}

\section{Pluralismo en tipos de medios}

\begin{tabular}{l|l|}
$\begin{array}{l}\text { No hay legislación específica para televisión } \\
\text { comunitaria, sólo radiodifusión comunitaria. }\end{array}$ & $\begin{array}{l}\text { La ley otorga reconocimiento legal e igualitario a } \\
\text { los tres tipos de medios }\end{array}$ \\
\hline $\begin{array}{l}\text { Hay disposiciones discriminatorias para el } \\
\text { sector sin fines de lucros }\end{array}$ & No hay disposiciones discriminatorias. \\
\hline
\end{tabular}

\section{Medios públicos}

Sólo hay un medio público: Televisión Nacional que debe autofinanciarse $y$ no recibe aportes del Estado.

EI directorio de TVN se decide en sesión secreta en el Senado.

No hay instancias de participación ciudadana
Se crea RTA S.E. que reúne a todos los medios públicos del país, reciben apoyo estatal a través de la Ley de Presupuesto y de impuesto específico.

Los nombres de los candidatos se publicitan previamente y se debate en Congreso. Consejo Consultivo ejerce "control social".

\section{Gestión del espacio radioelectrónico}

El directorio de la Autoridad de Aplicación (CNTV) se decide en sesión secreta en el Senado.

Las licencias son indefinidas para los canales pre 1992 y de 25 años, prorrogables por otros 25, para los canales privados post 1992.

La renovación la decide solamente el CNTV
El directorio Autoridad de Aplicación (AFSCA) se decide públicamente en el Congreso.

Licencias duran 10 años y se pueden prorrogar por otros diez, para todos.

La renovación es decidida por el AFSCA, previas audiencias públicas en la localidad respectiva. 


\begin{tabular}{|l|l|}
\multicolumn{2}{c}{ Límites a la concentración } \\
$\begin{array}{l}\text { No los hay, salvo en para las radios } \\
\text { comunitarias. }\end{array}$ & $\begin{array}{l}\text { Se establece } n^{\circ} \text { limitado de licencias por actor; se } \\
\text { impiden monopolios. }\end{array}$ \\
\hline
\end{tabular}

\section{Referencias}

ALEGRE, Pablo (2012): "Los giros a la izquierda en el Cono Sur: Gobiernos progresistas y alternativas comparadas de desarrollo en perspectiva comparada", en POUSADELA, Inés: Las izquierdas latinoamericanas. Argentina, Clacso, pp.3175.

BECERRA, Martín y MASTRINI, Guillermo (2009): Los dueños de la palabra. Buenos Aires, Prometeo.

BOURDIEU, Pierre (1997): Sobre la televisión. Barcelona, Gedisa.

BOURDIEU, Pierre (1988): Cosas Dichas. Barcelona, Gedisa.

BOWMAN, Shyane y WILLIS, Chris (2003): We Media. USA, American Press Institute.

BULLA, Gustavo (2011): "Participación: concepto clave en la Ley de Servicios de Comunicación Audiovisual", en BARANCHUK, Mariana y RODRÍGUEZ, Javier: Ley 26.522: hacia un Nuevo paradigma en comunicación”. Argentina, UNLZ, pp.93-104.

COMISIÓN INTERAMERICANA DE DD.HH. (2000): Declaración de Principios de Libertad de Expresión. Corte Interamericana de DD.HH.

CORRALES, Osvaldo y SANDOVAL, Juan (2005): "Concentración del mercado de los medios, pluralismo y libertad de expresión”. Colección Ideas, n5 (53), pp. 1-21.

DE CHARRAS, Diego (2011): "Pluralismo y Diversidad: dos ejes sustanciales de la agenda de regulción de los medios audiovisuales", en BARANCHUK, Mariana y RODRÍGUEZ, Javier: Ley 26.522: hacia un Nuevo paradigma en comunicación. Argentina: UNLZ, pp. 67-91.

DECLARACIÓN CONJUNTA SOBRE DIVERSIDAD EN LA RADIODIFUSIÓN (2007): Mecanismos para la promoción de la libertad de expresión.

DRAGOMIR, Marius (2007): "Concentración de medios en Europa”. Diálogo Político; núm.3, pp. 69-90.

ELLNER, Steve (2006): "The Defensive Strategy on the Left in Latin America: Objective and Subjective Conditions in the Age of Globalization". Science \& Society, $\mathrm{n}^{\mathrm{o}}$ 70:3 (July), pp. 397-410.

ESPINOSA, Eugenio (2012): “Crisis económica y cambios políticos y sociales en América Latina”, en ESTRADA, Javier: La crisis capitalista mundial y América Latina. Buenos Aires, Clacso, pp.123-143.

ESTAY, Jaime (2012): "El neodesarrollismo a dos décadas de "transformación productiva con equidad; balance y reformulaciones.", en ESTRADA, Javier: La crisis capitalista mundial y América Latina. Buenos Aires, Clacso, pp. 233-24. 
FAIRCLOUGH, Norman (1997): Media Discourse. London, Arnold.

FAINGEZICHT DE FISHMAN, Aída (2007): "La era de los oligopolios de la comunicación". Diálogo Político, no 3, pp. 111-118.

GARGARELLA, Roberto (2010): "El nuevo constitucionalismo latinoamericano". Crítica y Emancipación, no 2(3), pp. 169-187.

HEVIA, Renato (2001): "Ley de Prensa: el derecho a la información”. Asuntos Públicos, Informe $\mathrm{n}^{\mathrm{o}}$ 50, pp. 1-6.

IGARZA, Roberto (2010): "Gestión de la participación de los usuarios: control de las herramientas 2.0 de la versión en línea de los diarios de mayor tirada en Argentina". Conexiones; $\mathrm{n}^{\mathrm{o}} .2$ (1), pp. 5-28.

KAPLÚN, Gabriel (2010): "La nueva ley de Radiodifusión Comunitaria en Uruguay: el largo camino de la democratización de las comunicaciones", en Portal Unesco: http://portal.unesco.org/ci/en/files/29749/12701189987Uruguay_community_radio _law.pdf. [fecha de consulta, abril de 2012].

LEMOS, Hélio (2010): “A Conferencia Nacional de Comunicação: da liberdade de expressao à censura mediática", en SEL, Susana: Políticas de Comunicación en el Capitalismo Contemporáneo. Buenos Aires, Clacso, pp.211-230.

MAUERSBERGER, Christof (2012): "To be prepared when the time has come: Argentina's new media regulation and the social movement for democratizing broadcasting". Media, Culture \& Society, n $34(5)$, pp. 588-605.

MERAZ, Sharon (2011): The fight for "how to think". Journalism, vol. 12(1), pp. 118-142.

REIG, Ramón (2011): Los dueños del periodismo. Barcelona, Gedisa.

SEL, Susana (2010): "Actores sociales y espacio público:. Disputas por la ley de servicios de comunicación audiovisual en Argentina", en SEL, Susana: Políticas de Comunicación en el Capitalismo Contemporáneo. Buenos Aires, Clacso, pp. 183209.

TIRONI, Eduardo y SUNKEL, Guillermo (1993): "Modernización de las comunicaciones y democratización de la política". Estudios Públicos, nº. 52: pp. 1-32.

THOMPSON, John (1998): "Los media y la modernidad”. Barcelona, Paidós.

UNESCO (2008): Indicadores de Desarrollo Mediático. Naciones Unidas.

UNESCO (2003): Estudio comparativo de legislaciones de trece paises. Unesco: División de Libertad de Expresión.

VARESI, Gastón (2012): "Crisis mundial, modelo de acumulación y lucha de clases en la Argentina actual", en ESTRADA, Javier: La crisis capitalista mundial y América Latina. Buenos Aires, Clacso, pp. 145-157.

VERANO, Alejandro (2011): "El resurgimiento de la comunicación audiovisual pública", en BARANCHUK, Mariana y RODRÍGUEZ, Javier: Ley 26.522: hacia un Nuevo paradigma en comunicación”. Argentina, UNLZ, pp. 109- 121. 